\title{
Micro Coriolis Mass Flow Sensor with Extended Range for a Monopropellant Micro Propulsion System
}

\author{
Joost C. Lötters $^{1,2}$, Jarno Groenesteijn ${ }^{2}$, Marcel A. Dijkstra ${ }^{2}$, Harmen Droogendijk ${ }^{2}$, \\ Theo S.J. Lammerink ${ }^{2}$, Remco J. Wiegerink ${ }^{2}$ \\ ${ }^{1}$ Bronkhorst High-Tech BV, Nijverheidsstraat 1A, 7261 AK Ruurlo, The Netherlands \\ j.c.lotters@bronkhorst.com \\ ${ }^{2}$ MESA+ Institute for Nanotechnology, University of Twente, Enschede, The Netherlands
}

\begin{abstract}
:
We have designed and realised a micromachined micro Coriolis flow sensor for the measurement of hydrazine $\left(\mathrm{N}_{2} \mathrm{H}_{4}\right.$, High Purity Grade) propellant flow in micro chemical propulsion systems. The sensor should be able to measure mass flow up to $6 \mathrm{mg} / \mathrm{s}$ for a single thruster or up to $24 \mathrm{mg} / \mathrm{s}$ for four thrusters. The sensor will first be used for measurement and characterisation of the micro thruster system in a simulated space vacuum environment. Integration of the sensor chip within the micro thruster flight hardware will be considered at a later stage. The new chip has an increased flow range because of an integrated on-chip bypass channel. First measurement results have demonstrated an increase in flow range which corresponds well to the designed bypass ratio.
\end{abstract}

Key words: micro Coriolis flow sensor, hydrazine flow measurement, surface channel technology, MEMS fabrication technology, micro chemical propulsion system.

\section{Introduction}

The EU FP7 project PRECISE focuses on the research and development of a MEMS-based monopropellant micro Chemical Propulsion System $(\mu \mathrm{CPS})$ for highly accurate attitude control of satellites [1]. The availability of $\mu \mathrm{CPS}$ forms the basis for defining new mission concepts such as formation flying, advanced robotic missions and rendezvous maneuvers. These concepts require propulsion systems for precise attitude and orbit control maneuverability. Within PRECISE, research is performed towards a micro Coriolis mass flow sensor for measurement of the hydrazine propellant flow. The sensor will first be used for measurement and characterization of the micro thruster system in a simulated space vacuum environment. Integration of the sensor chip within the micro thruster flight hardware will be considered at a later stage. The required flow range is up to $6 \mathrm{mg} / \mathrm{s}$ for one thruster and up to $24 \mathrm{mg} / \mathrm{s}$ for four thrusters together.

Coriolis flow meters [2-5] are mostly used for measuring large flow rates, since the relatively weak Coriolis forces are correspondingly harder to detect for small flows. In general, the signal to noise ratio is very sensitive to fabrication and construction errors, as well as external influences of temperature and mechanical nature.
In [6] we proposed to fabricate a micro Coriolis mass flow sensor using silicon nitride as the tube material. This resulted in a very thin (1.2 $\mu \mathrm{m})$ tube wall, so that the mass of the tube is small compared to the mass of the moving fluid. This was a significant improvement over [7] and [8], which use silicon as the tube material, leading to a relatively heavy and stiff tube. We demonstrated that a silicon nitride sensor could reach a resolution in the order of $3 \mu \mathrm{g} / \mathrm{s}$ [6], however at that time no readout structures were integrated and a laser vibrometer was needed to optically measure the out-of-plane Coriolis motion of the tube. In [9, 10], we added an integrated capacitive readout and we demonstrated liquid flow measurement with a full scale range of $0.3 \mathrm{mg} / \mathrm{s}$ and a measurement accuracy of $1 \%$ of full scale.

In this paper, we present a new design with an integrated bypass channel in order to extend the flow range from $0.3 \mathrm{mg} / \mathrm{s}$ to $6 \mathrm{mg} / \mathrm{s}$ as needed for the propellant flow measurement in the PRECISE project.

\section{Basic Structure and Operating Principle}

A Coriolis type flow sensor consists of a vibrating tube. An important advantage of Coriolis sensors is that they are only sensitive to the true mass flow, independent of flow profile, pressure, temperature and properties of the fluid (density, viscosity, etc.). 
Figure 1 shows a schematic drawing of the Coriolis sensor based on Lorentz force actuation and capacitive sensing. The tube is actuated in torsion mode, indicated by $\omega_{a m}$. A mass flow $\Phi_{m}$ inside the tube induces Coriolis forces that excite the other vibration mode, resulting in a vibration amplitude proportional to the mass flow. Both the actuation and the Coriolis movements are detected using two capacitors $\left(C_{1}\right.$ and $C_{2}$ in Figure 1$)$ at the outside of the loop. The mass flow can be extracted from the two output signals by detecting the phase difference, which is exactly proportional to the amplitude ratio of the Coriolis and actuation movements.

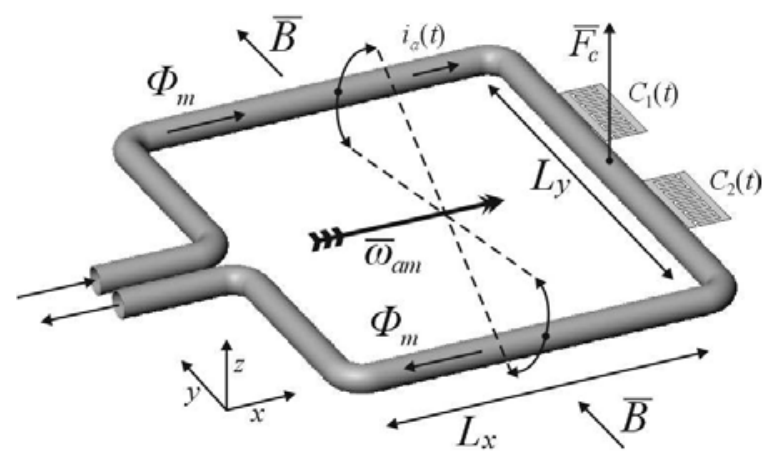

Fig. 1. Basic structure and operating principle of the micro Coriolis mass flow sensor

By applying a bypass ratio of approximately $1: 20$ respectively $1: 80$ the measurable flow range can be extended from $0.3 \mathrm{mg} / \mathrm{s}$ up to 6 respectively $24 \mathrm{mg} / \mathrm{s}$. A schematic overview of the bypass system is shown in Figure 2.

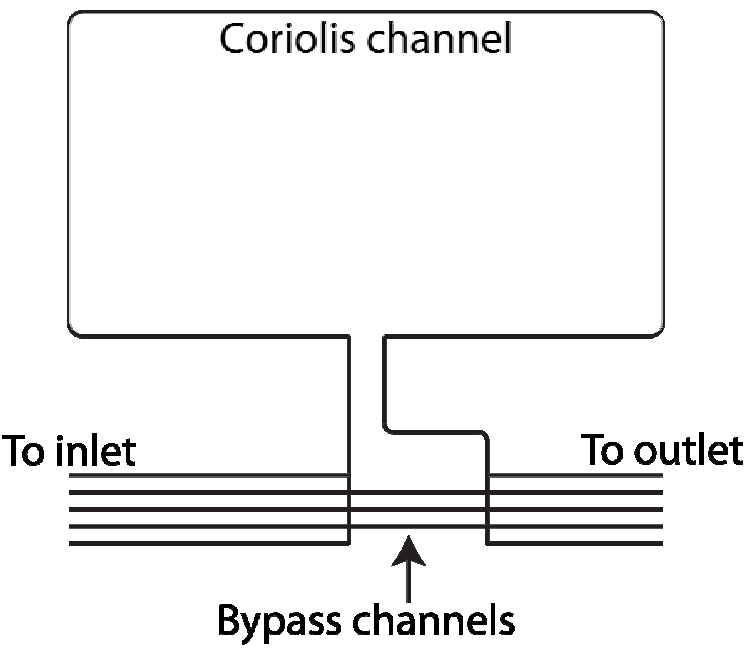

Fig. 2: Schematic overview of the bypass system. The length of the bypass channels and the amount of channels can be varied.
The bypass ratio can be calculated using Bernoulli's equation and Poiseuille's law for tube flow. Using only channels with the same diameter, the ratio depends only on the difference in channel length and the number of channels. Over the required flow range, equation (1) gives a good approximation for the bypass ratio:

Ratio $=\frac{l_{c} \cdot n_{b}}{l_{b}}$

In equation $(1), I_{c}[\mathrm{~m}]$ and $I_{b}[m]$ are the lengths of the Coriolis and bypass channels respectively and $n_{b}[-]$ is the amount of bypass channels. At very high flows, the bypass-ratio will decrease.

Figure 3 shows the mask lay-out of the sensor chip which measures $7.5 \times 15 \mathrm{~mm}$, the chip is designed for a bypass-ratio of 1:31.

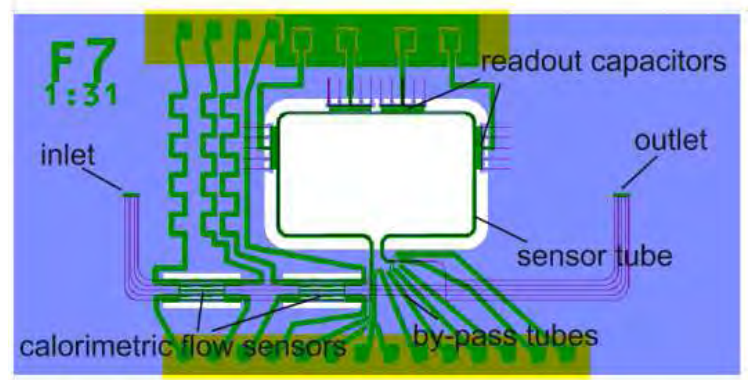

Fig. 3. Mask lay-out of the micro Coriolis mass flow sensor with bypass system.

\section{Fabrication}

Here we give a brief summary of the fabrication process. A more detailed description can be found in [10].

Starting with a highly doped $<100>p++$ wafer, a $500 \mathrm{~nm}$ thick low stress LPCVD silicon-rich silicon nitride $\left(\mathrm{Si}_{x} \mathrm{~N}_{\mathrm{y}}\right)$ layer is deposited. Then the fluidic inlet/outlet holes are etched from the backside of the wafer using the $\mathrm{Si}_{x} \mathrm{~N}_{y}$ layer at the top side as etch stop (Fig. 4a). Next, a $1 \mu \mathrm{m}$ thick TEOS (tetraethyl orthosilicate) oxide layer is deposited and removed from the front side of the wafer. Then a $50 \mathrm{~nm}$ layer of chromium is sputtered on the front side of the substrate. This chromium layer is patterned using a mask containing arrays of $5 \times 2 \mu \mathrm{m}$ holes, spaced 3 $\mu \mathrm{m}$ apart. This pattern forms the centerline of the final channel. The pattern is then transferred into the nitride layer by reactive ion etching and subsequently the channels are etched in the silicon using isotropic plasma etching (Fig. 4b). The TEOS layer and chromium mask are then removed and another $\mathrm{Si}_{x} \mathrm{~N}_{\mathrm{y}}$ layer is grown with a thickness of $1.8 \mu \mathrm{m}$ to form the channel walls and seals the etch 
holes in the first nitride layer (Fig. 4c). A 10/200 $\mathrm{nm}$ layer of chromium and gold is sputtered (chromium serving as the adhesion layer for gold) and patterned to create the metal electrodes for actuation and readout (Fig. 4d). Next, the release windows are opened by reactive ion etching of the $\mathrm{Si}_{x} \mathrm{~N}_{\mathrm{y}}$ layer (Fig. $4 \mathrm{e}$ ) and the structure is released by isotropic silicon plasma etching (Fig. 4f)).
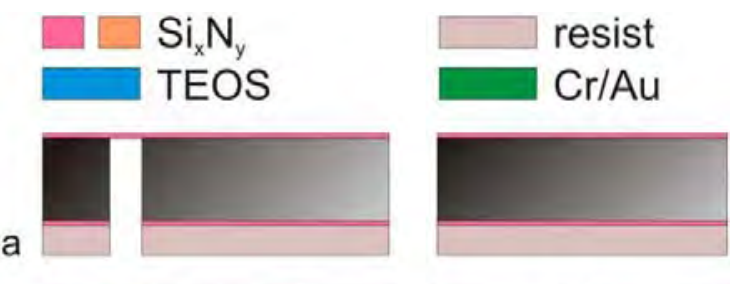

b
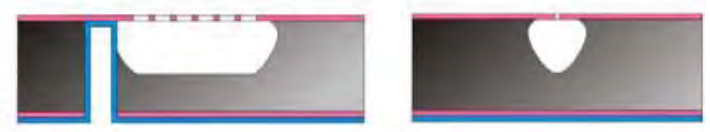

C

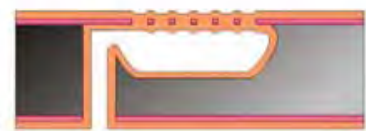

d

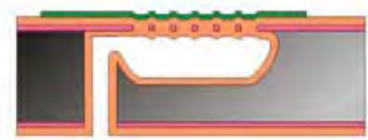

e

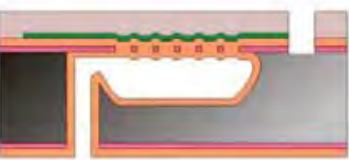

f
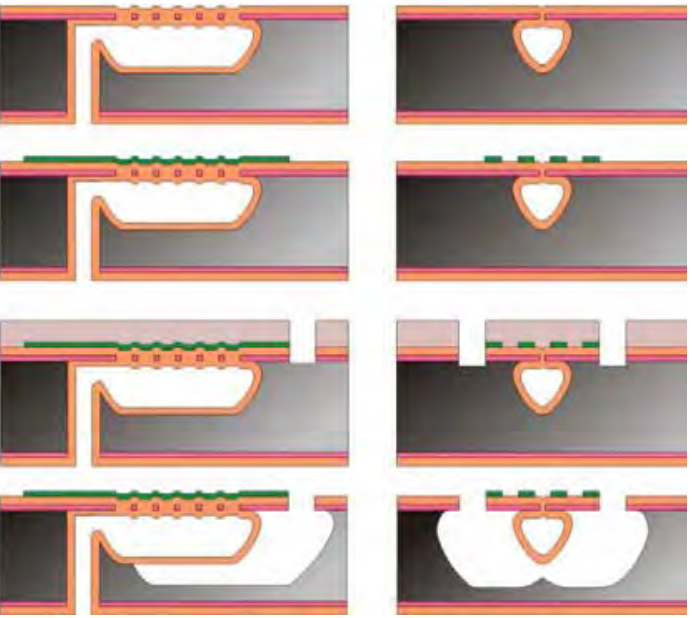

Fig. 4. Fabrication process.

Figure 5 shows a photograph of a fabricated sensor chip. The sensor tube with dimensions $L_{x}=2.5 \mathrm{~mm}$ and $L_{y}=4 \mathrm{~mm}$ is clearly visible in the center of the chip. The tube diameter is approximately $40 \mu \mathrm{m}$. The entire chip measures $7.5 \mathrm{~mm} \times 15 \mathrm{~mm}$.

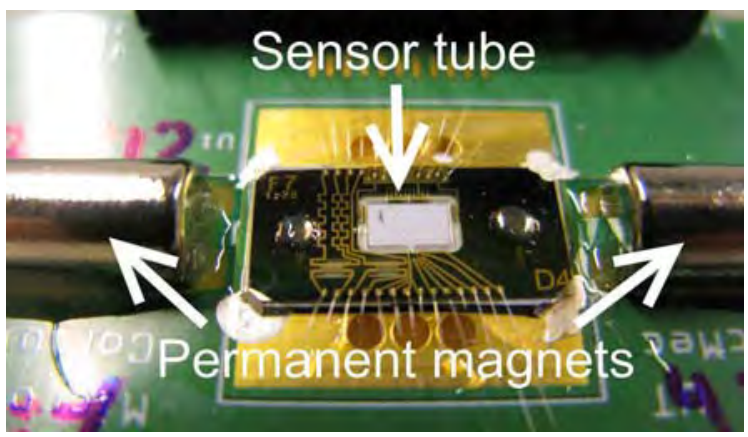

Figure 5: Photograph of the fabricated micro Coriolis flow sensor chip with bypass system.

\section{Interface electronics}

\section{Actuation}

As mentioned earlier, actuation of the sensor is achieved by Lorentz forces using a constant external magnetic field in combination with an alternating current. The permanent magnetic field is created by two $\mathrm{NdFeB}$ rare earth magnets [11], placed on either side of the chip. The structure is actuated at the resonance frequency $\omega_{a m}$ and thanks to the quality factor of approximately 40 (in air) an actuation current amplitude of $2 \mathrm{~mA}$, corresponding to approximately $1 \mathrm{~mW}$ power dissipation, is sufficient to obtain vibration amplitudes in the order of $10 \mu \mathrm{m}$ at the outer corners of the sensor structure.

\section{Detection}

A mass flow inside the tube induces Coriolis forces as indicated by $F_{c}$ in Figure 1, resulting in an out-of-plane vibration of the tube. At maximum flow, the amplitude of the out-ofplane vibration is the order of $100 \mathrm{~nm}$. To be able to detect these deflections, a capacitive on-chip read-out structure is used consisting of comb-like structures which function as a parallel plate capacitor when the two combs are separated out-of-plane. Using comb structures has two important advantages: 1) it greatly simplifies the fabrication process because only a single metal layer is needed, and 2) it avoids squeezed film damping which would occur in a traditional parallel plate capacitive readout. A disadvantage is that the operation of the structure relies on a static deflection of the tube due to the stress caused by deposition of the metal layer, which may vary in time, between different chips and as a function of temperature. Fortunately, the signal of interest is in fact the ratio between the Coriolis induced displacement and the actuation displacement, which are both equally affected by a change in comb distance.

\section{Complete sensor system}

Figure 6 shows a schematic diagram of the complete sensor system with actuation and readout electronics. The comb-shaped readout capacitors are indicated by $C_{1}$ and $C_{2}$. The combs that are attached to the moving sensor tube are connected to a signal source with frequency $F_{\text {carrier }}$ equal to about $1 \mathrm{MHz}$. Two counter-phase signals are used so that substrate currents due to parasitic capacitance are largely eliminated. The fixed combs are connected to charge amplifiers and the resulting amplitude modulated signals are demodulated by multiplication with an in-phase reference signal using SA602 analog multipliers. 


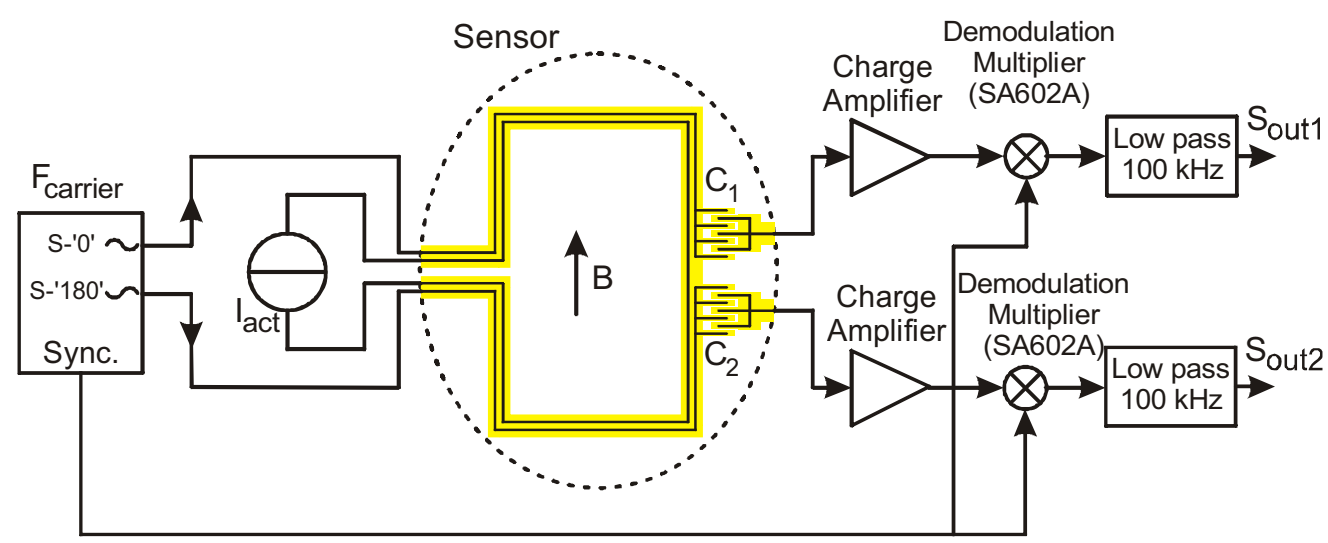

Fig. 6. Schematic diagram of the complete sensor system with actuation and readout electronics.

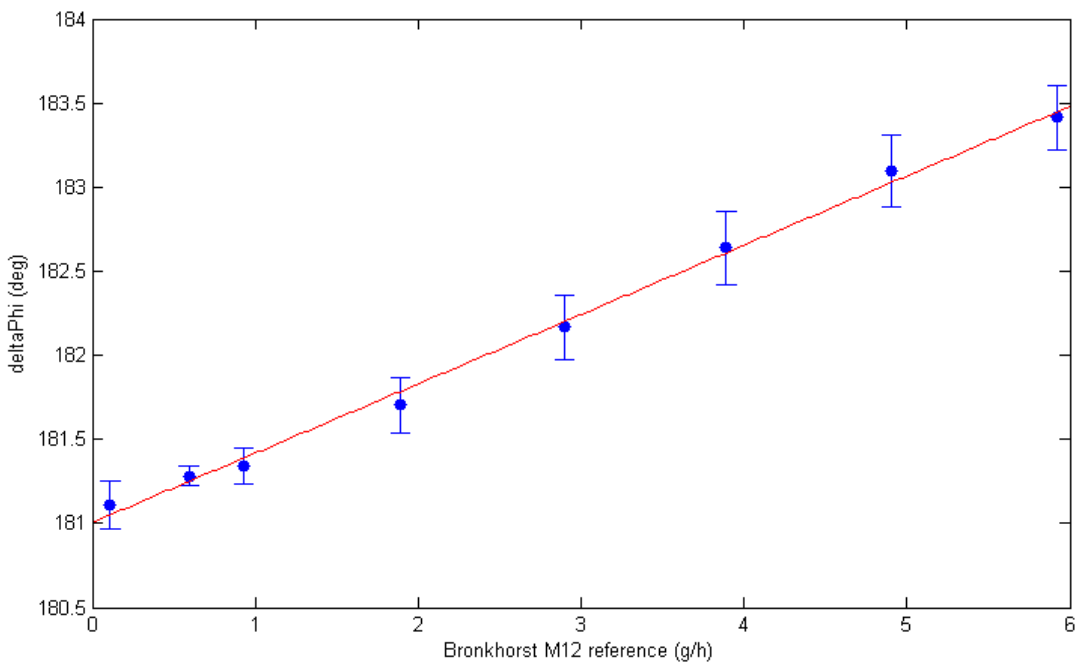

Fig. 8. Measurement results obtained with the micro Coriolis flow sensor chip with bypass system.

Low pass filters with relatively high cut-off frequency of $100 \mathrm{kHz}$ are used to prevent phase shift at frequencies below $3 \mathrm{kHz}$, i.e. the vibration frequency of the tube.

The sum of the two output signals $\left(S_{\text {out } 1}+S_{\text {out } 2}\right)$ is a measure for the difference in capacitance $\left(C_{1}-C_{2}\right)$, i.e. the actuation amplitude. The difference between the two output signals $\left(S_{\text {out } 1}-S_{\text {out } 2}\right)$ is a measure for the common variation in the capacitors due to the Coriolis effect. The measured mass flow can be extracted from the signals in two ways: 1) by measuring the sum and difference amplitudes separately using lock-in amplifiers at the vibration frequency of the tube and calculating the ratio between the amplitudes, and 2) by measuring the phase difference between $S_{\text {out } 1}$

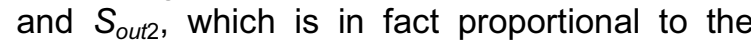
amplitude ratio. Both ways result in similar measurement accuracy.

\section{Measurement Results}

Measurements have been done with water using the setup shown in Figure 7. A Bronkhorst M12 mass flow controller was used to apply a mass flow.
Measurements have been done up to $6 \mathrm{~g} / \mathrm{h}$ (which is the equivalent of $1.67 \mathrm{mg} / \mathrm{s}$ ) at which the pressure drop over the device-under-test became too high for the setup due to several obstructed on-chip inlet channels. The results are shown in Figure 8. The measurement results shows a sensitivity of 0.41 degrees/(g/h), compared to 12.5 degrees $/(\mathrm{g} / \mathrm{h})$ for a sensor without bypass. This gives a bypass-ratio of 1:30.3, which is only slightly lower than the designed ratio of $1: 31$. The difference can easily be explained by variations in the fabrication process.

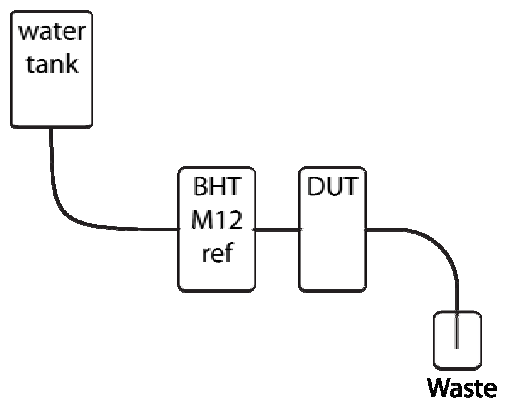

Fig. 7: Schematic overview of the measurement setup. The Bronkhorst M12 mass flow controller is used as a reference and to control the mass flow. 


\section{Conclusions}

We have designed, fabricated and tested a micromachined Coriolis flow sensor for the measurement of hydrazine $\left(\mathrm{N}_{2} \mathrm{H}_{4}\right)$ propellant flow in micro chemical propulsion systems. The sensor will be used for measurement and characterization of the micro thruster system in a simulated space vacuum environment. Required flow ranges are $6 \mathrm{mg} / \mathrm{s}$ for a single thruster and $24 \mathrm{mg} / \mathrm{s}$ for four thrusters. To reach the required flow range an on-chip bypass system was integrated. Initial measurements with water demonstrated an increase of the flow range which corresponds well to the designed bypass ratio.

\section{Acknowledgement}

This research is part of the PRECISE project (www.mcps-precise.com) and the NanoNextNL programme (http://www.nanonextnl.nl).

\section{References}

[1] M. Gauer, D. Telitschkin, U. Gotzig, Y. Batonneau, $\mathrm{H}$. Johansson, M. Ivanov, P. Palmer, R.J. Wiegerink, 48th AIAA/ASME/SAE/ASEE Joint Propulsion Conference \& Exhibit 2012.

[2] R.C. Baker, Flow. Meas. Instrum., 5, 1994, pp. 229-246.

[3] A. Anklin, W. Drahm and M. Rieder, Flow. Meas. Instrum., 17, 2006, pp. 317-323.

[4] A. Mehendale, J.C. Lötters and J.M. Zwikker, Coriolis mass flow meter using contactless excitation and detection, EP Patent 1,719,983, 2006

[5] A. Mehendale, J.C. Lötters and J.M. Zwikker, Mass flow meter of the Coriolis type, EP Patent 1,719,982, 2006

[6] J. Haneveld, T.S.J. Lammerink, M. Dijkstra, H. Droogendijk, M.J. de Boer and R.J. Wiegerink, Proc. MEMS 2008, pp. 920-923.

[7] P. Enoksson, G. Stemme and E. Stemme, J. MEMS 6 (1997), pp. 119-125.

[8] D. Sparks, R. Smith, J. Cripe, R. Schneider, N. Najafi, Proc. IEEE Sensors Conference 2003, pp. 90-92.

[9] J. Haneveld, T.S.J. Lammerink, M.J. de Boer and R.J. Wiegerink, Proc. MEMS 2009, pp. 463466.

[10] J. Haneveld, T.S.J. Lammerink, M.J. de Boer, R.G.P. Sanders, A. Mehendale, J.C. Lotters, M. Dijkstra and R.J. Wiegerink, J. Micromech. Microeng., 20, 2010, 125001, doi:10.1088/0960$1317 / 20 / 12 / 125001$

[11] http://www.supermagnete.de 